Article

\title{
Infusion Process of Smart Grid-Related Technology Based on Coping Theory
}

\author{
Jaehun Joo \\ Department of Information Management, College of Management and Economics, Dongguk University, \\ 707 Sukjang-DongGyeongju, Gyeongbuk 780-714, Korea; givej@dongguk.ac.kr; Tel.: +82-54-770-2346
}

Received: 18 May 2019; Accepted: 17 June 2019; Published: 22 June 2019

\begin{abstract}
It is important that individuals use infusion of smart grid-related technology to its full potential in their life, from the perspectives of individuals as well as firms and society. Firms can expand the market of their products and services, and create new wealth and jobs; infusion of smart grid-related technology promotes a sustainable society. The present study empirically analyzes the process of diffusing the smart grid-related technology by using data collected from participants in a Jeju smart grid testbed or a carbon-free island project in Jeju, South Korea. Ten hypotheses regarding the relationships between awareness of smart grid-related technology; the coping process, including appraisal and adaptive acts; and infusion are tested. Policy implications are suggested.
\end{abstract}

Keywords: smart grid; electric vehicle; solar photovoltaic systems; coping theory; infusion; diffusion

\section{Introduction}

Smart grids are a typical example of an emergent convergence technology that integrates the energy industry and information technology (IT). Smart grids represent the next generation of intelligent electric power grids. Smart grids enable both suppliers and consumers of electricity to engage in two-way communication by incorporating IT into existing power grids for the optimization of energy efficiency and utilization [1-3]. South Korea is one of the leading countries for successfully implementing the diffusion of smart grid technologies. South Korea, together with the U.S., the E.U., and Japan, is one of the first-movers in the development of smart grids [1,4].

Photovoltaic (PV) systems and electric vehicles (EVs) are closely related to smart grids. NIST [5] suggested a conceptual model of smart grids including customers, markets, operations, service providers, generation including distributed energy resources (DER), transmission, and distribution. DER is associated with generation, storage, and demand response for maximizing energy efficiency. Demand response is an important resource of the market domain, because it manages electricity consumption at the consumer side and aims to improve energy efficiency [6]. Palensky and Dietrich [7] describe a taxonomy of demand response management and suggest new challenges related to demand response management.

PV systems are contained in the generation domain, and EV is one of the customer domains [5]. The Jeju smart grid testbed and carbon-free project, as part of the Korean smart grid plan, include PV and EV as well as smart grids. The common agenda of smart grids, PV, and EV is to respond to climate change and environmental concerns. Thus, in the present study, smart grid, PV, and EV are referred to as smart grid-related technology.

Smart grid-related technology has been introduced and diffused by government-private partnerships, with subsidies in many countries as well as South Korea [8,9]. Government-led projects or projects featuring government and private partnerships with subsidies may be successful at their adoption stage. However, the whole process ranging from pre-adoption to post-adoption, including infusion, may feature different results. 
There are no studies dealing with the diffusion of smart grid-related technology in terms of the entire process from adoption to infusion. Coping theory [10] allows researchers to simultaneously study the adoption and infusion of smart grid-related technology. The purpose of the present study is to analyze the relationships between users' awareness toward smart grid-related technology, its appraisal, its adaptation acts, and its infusion throughout the whole process from pre-adoption to post-adoption. Thus, the originality of the present paper comes from an integrated research model dealing with the infusion of smart grid-related technologies. As it is the stage of post-demonstration of the smart grid testbed in South Korea, findings in the present study will hopefully contribute to the successful diffusion of smart grid-related technologies and providing some practical lessons to academics and practitioners. In particular, the results of the present study are significant and useful to policy making because data were collected from users who participated in the Jeju smart grid testbed.

\section{Background}

\subsection{Smart Grid Plan in South Korea, Jeju Smart Grid Testbed, and Carbon-Free Island Jeju 2030}

The Korean government launched a master plan and roadmap for developing smart grid technology, business models, and their sequential implementation plans in 2009. The plan consists of three phases, as shown in Figure 1. The first phase (2010-2012) aimed at verifying smart grid-related technology in five areas by establishing the Jeju testbed. The second phase (2013-2020) expanded the smart grid to eight metropolitan regions, and the third phase (2021-2030) intends to build a nationwide smart grid. The plan includes five areas comprising the platform for implementing smart grid projects, including smart power grids, smart electricity services, smart renewable energy, smart transportation, and smart consumers, as shown in Figure 1.

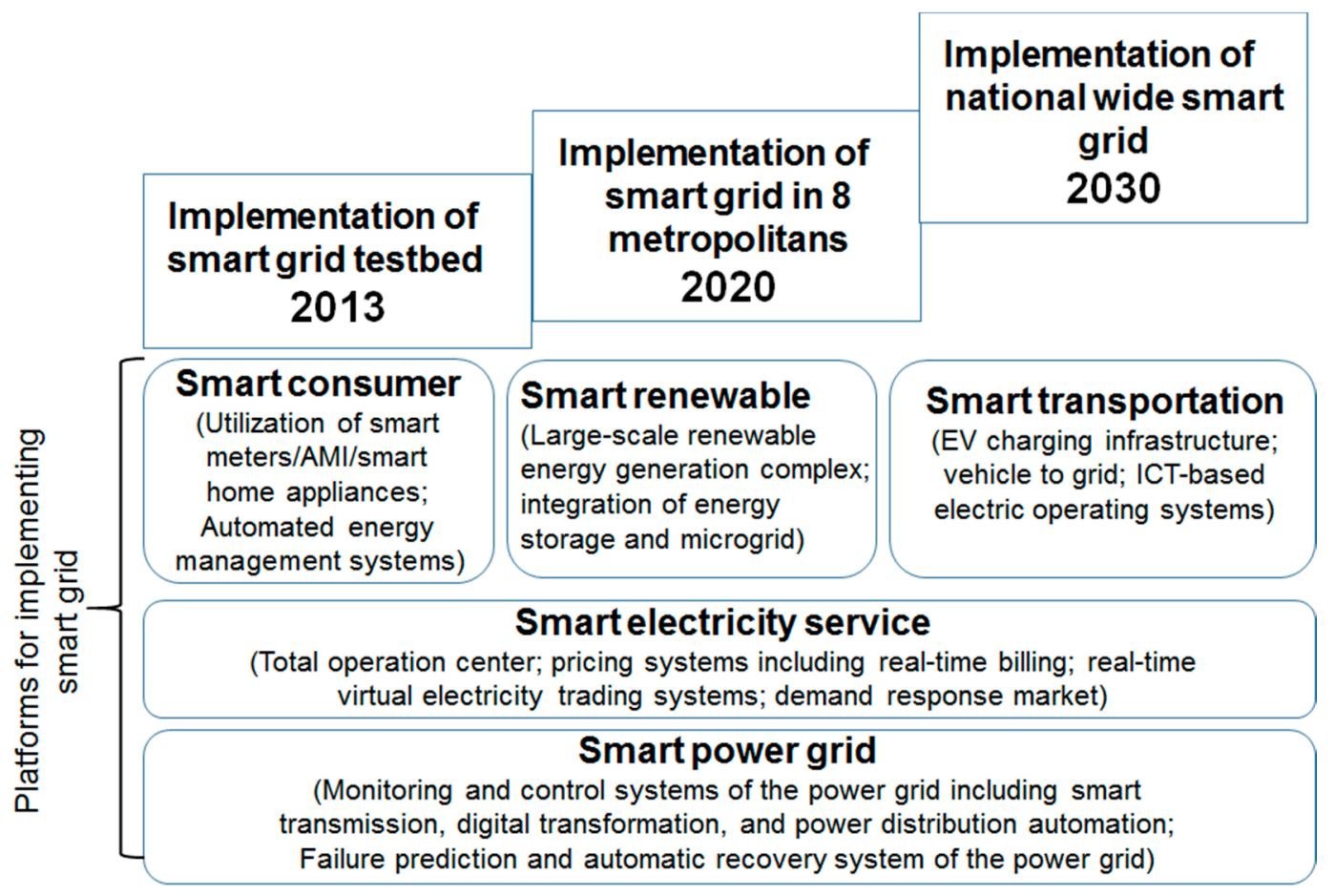

Figure 1. Roadmap for implementing smart grids in South Korea. Source: [11].

The Jeju smart grid testbed project, comprising the first phase, was completed in 2013. A total of 12 consortia were involved in the testbed project with government sponsorship. The reliability of 153 smart grid-related technologies in the five areas were tested in the Jeju testbed, in which a total of 3000 households located in 12 rural villages of Jeju island participated from 2010 to 2013. The total investment of the Jeju testbed projects was 240M US dollars ( $\$ 70$ million from the Korean 
government and $\$ 170$ million from the consortia of firms including KEPCO, [1]). Typical examples of smart grid-related technologies are AMI (advanced metering infrastructure), ESS (electric storage systems), EMS (energy management systems), EV charging, the connection of renewable energy such as PV systems, WPs (wind plants), and seawater desalination plants [8]. Smart grid devices and products, including smart meters and smart home appliances like refrigerators and washing machines equipped with ZigBee, were distributed to households of the Jeju testbed region free of charge, and smart grid resources such as EVs and their charging infrastructure and renewable energy systems were also provided to the smart grid testbed. Eighteen EVs were introduced to the Jeju testbed, with eight charging stations and 52 chargers [11].

After completing the testbed project as the first phase of smart grid plan in May 2013, Korean government and consortia of firms moved to eight metropolitan regions, including JeJu province, to initiate the second phase of the plan. This included introducing demand respond systems, vehicle to grid (V2G), microgrid, and building and factory management systems. However, users who participated in the Jeju testbed project had no more follow-up supports or sponsors from the consortia or government due to cuts in the governmental budget, and the second phase focused on metropolitan regions, including Jeju city (except the 12 rural villages).

"Carbon-Free Island Jeju by 2030", aligned with the smart grid plan of the Korean government, has been initiated to make Jeju province self-sufficient in energy use and has employed a smart grid since 2012. The project details include AMI, EMS, EV, and renewable energy systems. "Carbon-Free Island Jeju by 2030" aims to reduce the current $\mathrm{CO} 2$ emission level by 10 percent through the installation of wind power plants and PV systems, as well as switching all vehicles of Jeju into EVs, which will account for approximately 380,000 vehicles by 2030 .

\subsection{Coping Theory and Coping Model of User Adaptation}

Coping is the cognitive and behavioral efforts to manage specific internal or external demands that are appraised as taxing, exceeding individual resources, or being difficult to deal with [10]. In addition, coping refers to proactive adaptation to the events that are happening in the present and will continue to happen in the near future. Coping is very important to Lazarus and Folkman's [10] transactional theory of stress and coping, because persons experience stresses in their life and their adaptation depends on whether coping with stresses is effective or not. Coping theory refers to the research on how individuals appraise and cope with stress [10]. Coping theory has been applied to various areas of psychology, sociology, medicine, and social welfare. Beaudry and Pinsonneault [12] introduced the coping theory to business management, in particular information technology (IT) and information systems (IS), and Beaudry and Pinsonneault [12] suggested a coping model of user adaptation (CMUA) model drawing on the coping theory.

The CMUA encompasses the processes of user's awareness, appraisals, adaptation strategies, and outcomes of technology [12]. Lazarus and Folkman [10] suggested two types of appraisals. The primary appraisal is associated with the question "What is at stake for me in this situation?". The secondary appraisal refers to the assessment of resources that are available and useful for coping with stressful situations $[10,12]$. Typical adaptation strategies are problem-focused coping and emotion-focused coping $[10,12]$. Problem-focused coping focuses on a method dealing with the specific aspects of a situation by changing environment and issue itself, or one's self. Beaudry and Pinsonneault [12]'s benefits of maximizing and satisficing strategies are associated with problem-focused coping. Emotion-focused coping aims at controlling and changing one's emotions through various cognitive and behavioral efforts. Beaudry and Pinsonneault [12]'s disturbance handling or self-preservation strategies are examples of emotion-focused coping. Table 1 shows the extant research based on coping theory in the area of IT and IS. 
Table 1. Previous studies based on coping theory in the area of information technology (IT)/information systems (IS).

\begin{tabular}{|c|c|c|}
\hline Author(s) (Year) & Type of Technology & Overviews \\
\hline Beaudry and Pinsonneault [13] & General IT & $\begin{array}{l}\text { Proposed a conceptual model regarding the entire } \\
\text { process of infusion by applying appropriation theory } \\
\text { and coping theory }\end{array}$ \\
\hline Beaudry and Pinsonneault [12] & $\begin{array}{l}\text { Bank customer management } \\
\text { systems }\end{array}$ & $\begin{array}{l}\text { Defined user adaptation as the cognitive and } \\
\text { behavioral efforts to manage the situation associated } \\
\text { with IT issues and proposed the CMUA, which was } \\
\text { applied to a case of mangers in banks }\end{array}$ \\
\hline Liang and Xue [14] & General IT & $\begin{array}{l}\text { Drawing on coping theory and cybernetic theory, } \\
\text { suggested twelve propositions that explain users' } \\
\text { behavior of avoiding the threat of malicious IT }\end{array}$ \\
\hline Fadel and Brown [15] & Electronic medical systems & $\begin{array}{l}\text { Empirically examined the effect of IS perceptions on } \\
\text { primary and secondary appraisal by applying } \\
\text { CMUA. Data collected from IS users at a university } \\
\text { health center were employed to test the relationships } \\
\text { between IS perceptions and primary and secondary } \\
\text { appraisals }\end{array}$ \\
\hline Fadel [16] & Electronic medical systems & $\begin{array}{l}\text { Empirically examined relationships between IS } \\
\text { appraisals and adaptation behaviors } \\
\text { (problem-focused and emotion-focused coping) by } \\
\text { using CMUA }\end{array}$ \\
\hline Fadel [17] & Electronic medical systems & $\begin{array}{l}\text { Drawing on CMUA, empirically examined the } \\
\text { relationships between adaptation behaviors and IS } \\
\text { infusion }\end{array}$ \\
\hline D'Archy et al. [18] & General IT & $\begin{array}{l}\text { Drawing on coping theory, empirically examined the } \\
\text { relationship between employee stress due to } \\
\text { information security requirements and information } \\
\text { security policy violations }\end{array}$ \\
\hline Stein [19] & $\begin{array}{l}\text { University faculty productivity } \\
\text { software }\end{array}$ & $\begin{array}{l}\text { Empirically examined role of emotions responding to } \\
\text { IT stimulus event through an in-depth field study } \\
\text { with } 47 \text { semi-structured interviews, and found five } \\
\text { distinct patterns of use: exercising discretion, being a } \\
\text { good citizen, gaming the system, personalizing, and } \\
\text { opting out }\end{array}$ \\
\hline Bhattacherjee et al. [20] & $\begin{array}{l}\text { Computerized patient order entry } \\
\text { system in hospital }\end{array}$ & $\begin{array}{l}\text { Drawing on coping theory, identified four types of } \\
\text { user responses in mandatory IT use settings by } \\
\text { analyzing interview data: engaged, compliant, } \\
\text { reluctant, or deviant responses }\end{array}$ \\
\hline Gaudioso et al. [21] & General IT & $\begin{array}{l}\text { Examined the relationships between techno-stressors } \\
\text { occurring in any workplace using computers, coping } \\
\text { strategies, and work exhaustion as an outcome }\end{array}$ \\
\hline
\end{tabular}

\subsection{Infusion}

Infusion is the process of embedding technology (smart grid, PV, and EV) into personal life or work life and using it to its fullest potential. Zmud and Apple [22] defined infusion as "the extent to which the full potential of the innovation has been embedded within an organization's operational or managerial work systems." Regarding the diffusion of technology, the IT implementation stages consist of initiation, adoption, adaptation, acceptance, routinization, and infusion. At the organizational level, infusion is the process of using the IT application to its fullest potential and obtaining increased organizational effectiveness through the use of IT applications [22,23]. At the individual level, Jones et al. [24] defined infusion as "the extent to which a person uses technology to its fullest extent to enhance his or her productivity." Infusion refers to the measurement of technology use, and the degree of infusion depends on the benefits of the technology as perceived by the user [24].

\section{Research Model and Hypothesis}

Lazarus and Folkman [10] suggested the stress-coping-adaptation model describing the process of perceiving a stress, performing cognitive appraisals, and coping through adaptive acts. The CMUA encompasses appraisals assessing an IT event with its awareness, adaptation strategies, and outcomes that are divided into individual effectiveness, minimization of the negative consequences of the IT 
event, restoring personal emotional stability, and exit. Fadel and Brown [15] proposed a model describing the relationship between IS perceptions based on the theory of IS adoption and appraisal of IS based on coping theory. According to Lazarus and Folkman [10], cognitive appraisal occurs when a person perceives the threatening tendency of stress. Cognitive appraisal depends on how a person perceives the IT event. Drawing on coping theory and the CMUA, a research model is proposed, as shown in Figure 2. The research model includes the entire process of technology diffusion such as benefit and risk expectancy as user's awareness of technology, adaptation process, and infusion as an outcome of post-adoption of technology.

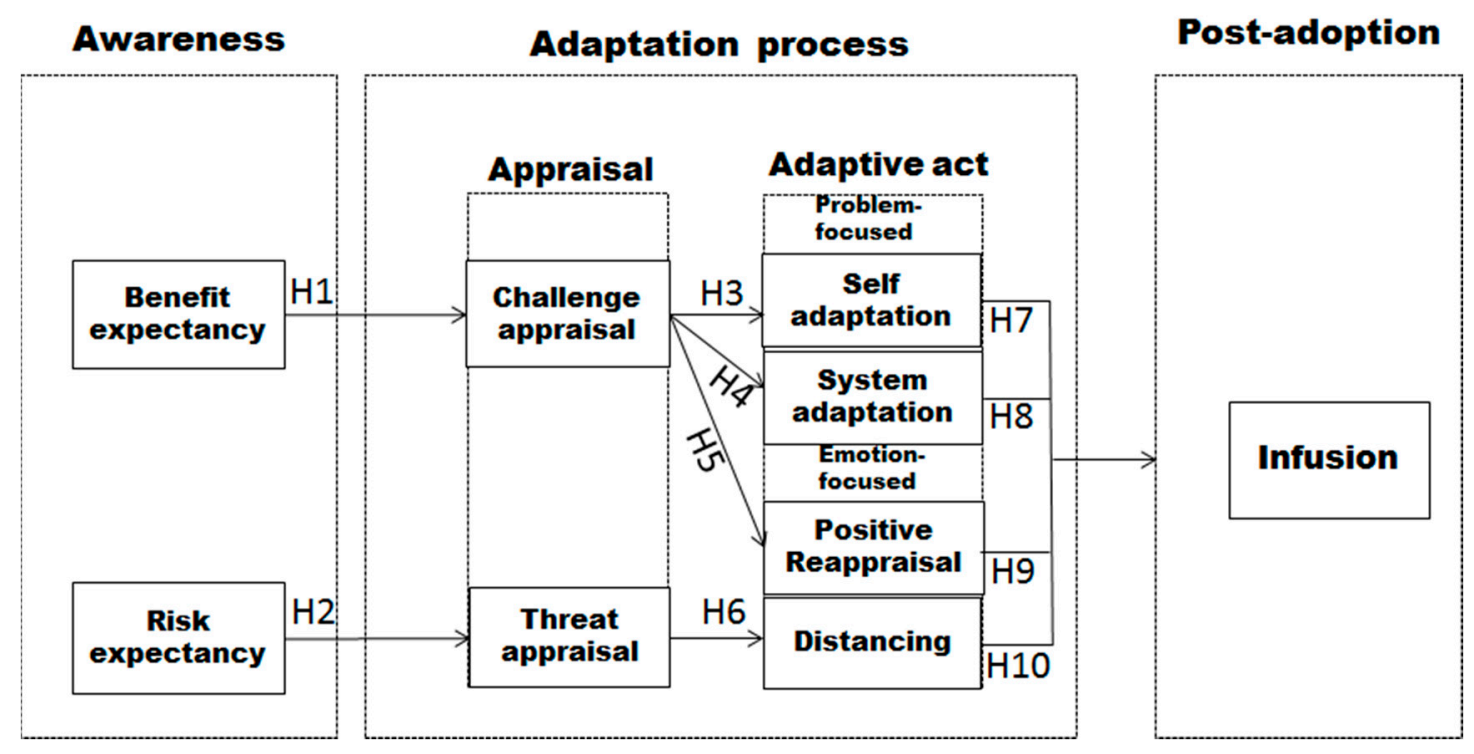

Figure 2. Research model.

According to Fadel and Brown [15], performance expectancy and effort expectancy influence how users assess an IS as the antecedents of cognitive appraisal of the coping process. Performance expectancy is one of IS perceptions in UTAUT (Unified Theory of Acceptance and Use of Technology) regarding IS adoption and use behavior [25]. The empirical study using data collected from electronic medical system (EMS) users found that performance expectancy of using the EMS positively influences challenge appraisal being viewed as an opportunity.

Perceived risk is associated with consumer behavior. Perceived risk negatively influences IT or IS adoption [26-28]. Users who identify technology as being risky assess technology as potentially dangerous or harmful to them.

Joo and Kim [1] analyzed data collected from in-depth interviews with 41 users of the smart grid in the Jeju testbed. They argued that benefit expectancy included demand increase for tourism, the construction of clean and pleasant environments, and local economic growth, as well as direct economic benefits such as saving electricity and reducing of heating or air conditioning costs. On the other hand, some users questioned whether smart grid technology is reliable and matured, and in particular, a few users worried about maintenance cost and future financial burdens although smart grid devices had been distributed to them free of charge during the testbed period. In the present study, benefit expectancy is defined as the degree to which a user expects that using the technology would help him or her to realize benefits in his or her life. Risk expectancy is defined as the degree to which a user perceived that using the technology would result in risky situations in their life, as shown in Appendix A.

Lazarus and Folkman [10] suggested irrelevant, benign/positive, and stress as the outcomes in response to "What is at stake for me in this situation." A stressful situation is appraised as a thereat if it seems likely to result in some damage, or as a challenge if it is viewed as an opportunity for gain or growth $[10,15]$. In the present study, the challenge appraisal refers to the degree to which a person 
assesses technology as a chance for gain or growth, whereas the threat appraisal is defined as the degree to which a person assesses technology as potentially resulting in harm or. Two hypotheses regarding the relations of the awareness and the appraisal in the research model are suggested as follows:

Hypothesis 1 (H1). Benefit expectancy positively influences challenge appraisal.

Hypothesis 2 (H2). Risk expectancy positively influences threat appraisal.

Many previous studies have dealt with the relationships between the appraisal of stressful events and an individual's coping behavior [10,12,16,29,30]. Beaudry and Pinsonneault [12] analyzed the relationships between appraisals including opportunity and threat, and problem-focused or emotion-focused acts as adaptation strategies through multiple case approach. According to Fadel [16]'s study of empirical analysis using data collected from users of electronic medical systems, the appraisal of information systems as a challenge is associated with engagement in both problem-focused adaptation and emotion-focused adaptation behaviors, in which the former includes self-adaptation and system adaptation and the latter consists of positive reappraisal and distancing/avoidance. Marakhimov and Joo [30] investigated the relationships between the appraisals as challenges or threats, and problem-focused and emotion-focused coping strategies by analyzing data collected from consumers of wearable devices. Challenge appraisal is positively associated with both problem-focused and emotion-focused coping behaviors [30]. Threat appraisal influences emotion-focused coping behavior [30]. Problem-focused adaptation is divided into self-adaptation and system adaptation strategies $[10,16]$. In the present study, self-adaptation is defined as the degree to which the user adapts to new technologies by making proactive efforts to learn new skills or communicate with others such as experts or suppliers, while system adaptation refers to the degree to which a user adapts to technology by making efforts to change its functionalities or features. Emotion-focused adaptation strategy includes positive reappraisal, which is defined as the degree to which a user attempts to create or ascribe positive meaning to the technology, and distancing/avoidance, which refers to the degree to which a user has wishful thinking or efforts to escape or detach the technology.

Joo and Kim [1] interviewed with 41 users who participated in the Jeju smart grid testbed in 2011. According to their study, users who considered the smart grid technology as an opportunity to change for better life or an opportunity to develop new events for helpful life had a proactive attitude toward diffusion of smart grids as described in the following statements:

"Now I am more knowledgeable than the provider's staff. I need to get economic benefits. So I studied. I followed around the technicians while they installed the system and asked questions to the staff. I installed for the first time in the world electronic appliances that use renewable energy. I can operate air conditioner, refrigerators, washing machines, kitchen appliances, and TVs by smartphones."

Users who assessed smart grid technology as a chance for gain or growth adapted it by making efforts to learn new skills, or to ascribe positive meaning to it, as described by informants [1]:

"I positively changed my attitude toward the smart grid technology after I experienced that my neighbor had benefits from it. Well, it saves money. Although $\mathrm{CO} 2$ reductions and other environmental benefits don't mean much to me, I am adopting it because it offers both convenience and financial benefits. I wasn't really interested in the smart grid at first. I didn't seek to learn. But as I became more exposed to it, I changed my mind and am somewhat interested. It was inconvenient at first but now I know it saves electricity. It is now convenient."

The following four hypotheses are proposed:

Hypothesis 3 (H3). Challenge appraisal positively influences self-adaptation. 
Hypothesis 4 (H4). Challenge appraisal positively influences system adaptation.

Hypothesis 5 (H5). Challenge appraisal positively influences positive reappraisal.

Hypothesis 6 (H6). Threat appraisal positively influences distancing/avoidance.

Adaptation efforts result in various outcomes or sequences. These outcomes depend on adaptation strategies. Users can increase the effect of technology potential, or can withdraw from or exit the situation [12]. Infusion is one of the outcomes of adaptation acts. Fadel [16] investigated the relationship between adaptation strategies and IS infusion. Problem-focused adaptation, which refers to efforts to change one's self or change the environment (functionalities and features of IS), positively influences IS infusion [17]. According to Fadel [17], emotion-focused coping acts include positive reappraisal and distancing/avoidance. Emotion-focused strategies are associated with IS infusion [17]. Marakhimov and Joo [30] suggested extended use as an outcome of adaptation strategies, and argued that both problem-focused adaptation and emotion-focused adaptation strategies were related to the extended use of wearable devices. Roldán et al. [31] examined the relationships between frequency of use, routinization, infusion, and social integration by analyzing data collected from users of a social network site. Infusion plays a mediating role in the relationships between frequency of use or routinization, and social integration [31]. The following four hypotheses regarding relationships between adaptation strategies and infusion are proposed:

Hypothesis 7 (H7). Self adaptation positively influences infusion.

Hypothesis 8 (H8). System adaptation positively influences emotion.

Hypothesis 9 (H9). Positive reappraisal positively influences infusion.

Hypothesis 10 (H10). Distancing/avoidance negatively influences infusion.

\section{Methodology and Analysis}

\subsection{Measurement and Sampling}

Measurement scales regarding total nine constructs with 33 question items were developed and adapted from extant studies, as shown in Appendix A. Five constructs, including benefit expectancy, risk expectancy, challenge appraisal, threat appraisal, and infusion were measured by the reflective scales, in the same way as previous studies $[16,17,24]$. Consistent with previous studies [17], four constructs related to problem-focused adaptation, including self adaptation and system adaptation, and emotion-focused adaptation, including positive reappraisal and distancing/avoidance, were conceptualized as formative constructs. All question items in Appendix A were measured by five-point Likert scales ranging from 1 (strongly disagree) to 5 (strongly agree).

226 valid samples were collected for analysis. Jeju Special Self-Governing Province provided a list of users who had participated in the Jeju smart grid testbed and the plan of EV supply in Jeju. A survey team firstly contacted the participants via email and telephone calls. Then, the team members met all participants who agreed to participate in the survey. Users completed the questionnaire with the assistance of surveyors, as some elderly users wanted assistance with the questionnaire.

Purposive sampling method, which is a nonprobability method, was employed to collect data. Purposive sampling is more effective when population is composed of only limited people. After the Jeju testbed was completed in May 2013, there were no more follow-up support projects except expansion of government subsidies in areas of PV systems and EVs. Thus, only limited people are still using the smart grid technology in Jeju. It is difficult to apply a random probability sampling to the data collection because of only limited users in population and face-to-face surveys. 


\subsection{Analysis}

SPSS Statistics (version 23) and Smart PLS (version 3.0) were used to analyze the data. Table 2 shows the demographic characteristics of respondents. The ratio of respondents over 50 years old is $44.3 \%$, because the smart grid testbed is located in rural areas of Jeju Island. The average usage experience is 2.6 years. The ratios of users of smart grid/solar photovoltaics and electric vehicle are $56 \%$ and $44 \%$, respectively.

Table 2. Demographic characteristics.

\begin{tabular}{lllll}
\hline Variable & Categories & Frequency & Percent \\
\hline \multirow{2}{*}{ Gender } & Male & 131 & 58.0 \\
\cline { 2 - 4 } Age & Female & $20-29$ & 22 & 42.0 \\
\cline { 2 - 4 } & $30-39$ & 28 & 9.7 \\
\cline { 2 - 4 } & $40-49$ & 76 & 12.4 \\
\cline { 2 - 4 } & $50-59$ & 46 & 33.6 \\
\hline \multirow{3}{*}{ Experience } & Over 60 & 54 & 20.4 \\
\cline { 2 - 4 } & Under 1 year & 74 & 23.9 \\
\cline { 2 - 4 } & 3 years & 89 & 32.7 \\
\cline { 2 - 4 } & 4 years & 17 & 39.4 \\
\cline { 2 - 4 } & Over 5years & 6 & 7.5 \\
\hline \multirow{2}{*}{ Technology } & Smart grid and solar photovoltaics & 127 & 2.7 \\
\cline { 2 - 4 } & Electric vehicle & 99 & 17.7 \\
\hline
\end{tabular}

Table 3 shows the basic information for each construct, including numbers of measurement items, mean, standard deviation, Cronbach's alpha, and the type of constructs. All Cronbach's alphas of reflective constructs exceeded the 0.7 threshold for internal consistency [32,33].

Table 3. Means, standard deviations (SD), and Cronbach's alpha.

\begin{tabular}{llllll}
\hline Construct & No. of Items & Mean & SD & Cronbach's alpha & Type of Constructs \\
\hline Benefit Expectancy (BE) & 6 & 4.797 & 0.884 & 0.886 & Reflective \\
\hline Risk Expectancy (RE) & 3 & 2.895 & 1.033 & 0.833 & Reflective \\
\hline Challenge Appraisal (CA) & 2 & 3.894 & 0.813 & 0.840 & Reflective \\
\hline Treat Appraisal (TA) & 4 & 1.903 & 0.850 & 0.908 & Reflective \\
\hline Self Adaptation (SA) & 5 & 2.639 & 0.991 & N/A & Formative \\
\hline System Adaptation (YA) & 3 & 2.690 & 1.032 & N/A & Formative \\
\hline Positive Reappraisal (PR) & 4 & 3.215 & 0.976 & N/A & Formative \\
\hline Distancing (DS) & 2 & 2.675 & 0.511 & N/A & Formative \\
\hline Infusion (IN) & 4 & 3.590 & 0.865 & 0.895 & Reflective \\
\hline & & N/A: Not Applicable. & &
\end{tabular}

Exploratory factor analysis for reflective items was conducted using principal component analysis with Varimax rotation. The first factor, benefit expectancy, explains $31.89 \%$ of total variance and indicates that the possibility of common method bias is too low [34]. 


\subsection{Validity and Hypothesis Test}

Cronbach's alpha, composite reliability (CR), and average variance extracted (AVE) are used to confirm convergent validity. Cronbach's alpha and composite reliability (CR) for all reflective constructs exceed the 0.7, threshold recommended by Fornel and Larcker [35], and AVE values also exceed 0.5. Table 4 shows the statistical data for confirming convergent and discriminant validity. Numbers on the diagonal are the square root of AVE for each reflective construct. The square root of AVE for each reflective construct is higher than its correlations with other constructs.

Table 4. Convergent and discriminant validity.

\begin{tabular}{|c|c|c|c|c|c|c|c|c|c|c|c|}
\hline & CR & AVE & BE & RE & CA & TA & SA & YA & PR & DS & IN \\
\hline $\mathrm{BE}$ & 0.913 & 0.637 & 0.798 & & & & & & & & \\
\hline RE & 0.898 & 0.748 & $-0.189 *$ & 0.864 & & & & & & & \\
\hline $\mathrm{CA}$ & 0.926 & 0.862 & 0.517 & -0.181 & 0.928 & & & & & & \\
\hline TA & 0.935 & 0.783 & -0.114 & 0.201 & -0.136 & 0.884 & & & & & \\
\hline SA & NA & NA & 0.282 & -0.252 & 0.344 & -0.136 & NA & & & & \\
\hline YA & NA & NA & 0.411 & -0.217 & 0.348 & -0.058 & 0.556 & NA & & & \\
\hline PR & NA & NA & 0.426 & -0.221 & 0.580 & -0.216 & 0.580 & 0.586 & NA & & \\
\hline DS & NA & NA & -0.193 & 0.126 & -0.260 & 0.392 & -0.211 & -0.120 & -0.274 & NA & \\
\hline IN & 0.927 & 0.762 & 0.356 & -0.056 & 0.402 & -0.418 & 0.472 & 0.436 & 0.573 & -0.465 & 0.872 \\
\hline
\end{tabular}

Composite reliability (CR) and average variance explained (AVE). ${ }^{*}$ Inter-construct correlations; numbers on the diagonal are the square root of AVE for each construct.

HTMT (heterotrait-monotrait ratio) was suggested as a criterion of discriminant validity by Henseler et al. [36]. Discriminant validity is satisfactory for a given pair of reflective constructs, if the HTMT value is below 0.90 [37]. All values in Table 5 are less than 0.9 .

Table 5. Heterotrait-monotrait ratio (HTMT).

\begin{tabular}{ccccc}
\hline & BE & RE & CA & TA \\
\hline BE & & & & \\
\hline RE & 0.228 & & & \\
\hline CA & 0.593 & 0.226 & & \\
\hline TA & 0.128 & 0.221 & 0.156 & 0.460 \\
\hline IN & 0.398 & 0.0083 & 0.461 & \\
\hline
\end{tabular}

Multicollinearity for checking intercorrelation between independent variables did not exist for all reflective and formative variables because all VIF (variance inflation factor) values were less than the cutoff criterion of 5 [32,37].

In general, when using PLS, SRMR (standardized root mean square residual) is employed as a measure of approximate fit of the structural model [37]. The structural model has good fit, because the SRMR value of 0.057 is less than the cutoff of 0.08 [38].

Path analysis using SmartPLS was used to test ten hypotheses. As shown in Table 6, all hypotheses except $\mathrm{H} 8$ are supported. Hypotheses, $\mathrm{H} 1$ to $\mathrm{H} 6, \mathrm{H} 9$, and $\mathrm{H} 10$ are supported at the significance level of 0.01 , and H7 is supported at the significance level of 0.05 . R-square, known as the coefficient of determination, is measured by the variance being explained through the model [39]. Chin [39] classified the level of explanatory power into "substantial" level with a threshold of 0.67 , "moderate" with a cutoff of 0.33 , and "weak" with a cutoff of 0.19 , respectively [37]. Table 7 shows the R-square values and their t-values. All R-squares are significant, except the threat appraisal variable. In particular, four 
variables related to problem-focused and emotion-focused adaptation behaviors explain $46 \%$ of the variance in fusion as an outcome of the adaptation process.

Table 6. Hypothesis test results.

\begin{tabular}{llllllll}
\hline Hypothesis & Path & VIF & Path Coefficient & Standard Deviation & $t$ & $p$ & Result \\
\hline $\mathrm{H} 1$ & $\mathrm{BE} \rightarrow \mathrm{CA}$ & 1.000 & 0.517 & 0.058 & 8.984 & 0.000 & Supported \\
\hline $\mathrm{H} 2$ & $\mathrm{RE} \rightarrow \mathrm{TA}$ & 1.000 & 0.201 & 0.073 & 2.767 & 0.006 & Supported \\
\hline $\mathrm{H} 3$ & $\mathrm{CA} \rightarrow \mathrm{SA}$ & 1.000 & 0.344 & 0.064 & 5.406 & 0.000 & Supported \\
\hline $\mathrm{H} 4$ & $\mathrm{CA} \rightarrow \mathrm{YA}$ & 1.000 & 0.348 & 0.065 & 5.346 & 0.000 & Supported \\
\hline $\mathrm{H} 5$ & $\mathrm{CA} \rightarrow \mathrm{PR}$ & 1.000 & 0.580 & 0.049 & 11.840 & 0.000 & Supported \\
\hline $\mathrm{H} 6$ & $\mathrm{TA} \rightarrow \mathrm{DS}$ & 1.000 & 0.392 & 0.087 & 4.511 & 0.000 & Supported \\
\hline $\mathrm{H} 7$ & $\mathrm{SA} \rightarrow \mathrm{IN}$ & 1.713 & 0.143 & 0.073 & 1.969 & 0.049 & Supported \\
\hline $\mathrm{H} 8$ & $\mathrm{YA} \rightarrow \mathrm{IN}$ & 1.753 & 0.126 & 0.071 & 1.786 & 0.075 & Not supported \\
\hline $\mathrm{H} 9$ & $\mathrm{PR} \rightarrow \mathrm{IN}$ & 1.848 & 0.326 & 0.067 & 4.856 & 0.000 & Supported \\
\hline $\mathrm{H} 10$ & $\mathrm{DS} \rightarrow \mathrm{IN}$ & 1.086 & -0.331 & 0.062 & 5.324 & 0.000 & Supported \\
\hline
\end{tabular}

Table 7. R-square.

\begin{tabular}{cccc}
\hline & R-Square & $\boldsymbol{t}$-Value & $p$-Value \\
\hline CA & 0.267 & 4.416 & 0.000 \\
\hline TA & 0.040 & 1.339 & 0.181 \\
\hline SA & 0.118 & 2.710 & 0.007 \\
\hline YA & 0.121 & 2.635 & 0.009 \\
\hline DS & 0.154 & 2.231 & 0.026 \\
\hline IN & 0.463 & 8.836 & 0.000 \\
\hline
\end{tabular}

\section{Conclusions}

The present study empirically analyzed the whole process of diffusing smart grid-related technology by using data collected from users of the Jeju smart grid testbed or carbon-free island project in Jeju, South Korea. In sum, benefit expectancy to smart grid-related technology positively influences challenge appraisal, whereas risk expectancy positively influences threat appraisal. Challenge appraisal positively affects self and system adaptations as problem-focused adaptation strategies, and also positively influences positive reappraisal as an emotion-focused adaptation strategy. Moreover, threat appraisal positively influences distancing/avoidance as an emotion-focused strategy. Self adaptation, positive reappraisal, and distancing/avoidance were significant determinants of infusion of smart grid-related technology. Self adaptation and positive reappraisal positively influence its infusion, whereas distancing/avoidance negatively influences its infusion. However, system adaptation acts have no significant effect on its infusion.

The self adaptation act, a problem-focused strategy, is more important than systems adaptation for infusion, which uses smart grid-related technology to its fullest potential or in the most familiar and efficient ways. Users of smart grid-related technology can maximize infusion by utilizing positive reappraisal acts or mitigating distancing/avoidance acts. It is important for users to assess smart grid-related technology as challenges rather than threats through benefit expectancy at the pre-adoption stage.

Implications for academics are as follows. The integrative research model based on the coping theory effectively explains the whole process of diffusing smart grid-related technology. The research model sheds light on the study regarding the infusion of technology at level of the individual. Infusion, which involves individuals using smart grid-related technology to its fullest potential in their life, is important from the perspectives of firms, society, as well as individuals. Research results found the variables that are significant to the diffusion of smart grid-related technology at each stage of 
awareness, the adaptation process, and infusion. A methodological approach including a research model can be applied to other emerging technologies.

Implications for practitioners and policy makers are drawn from the research results. Firms can expand the market of products and services and create new wealth and jobs, and infusion of smart grid-related technology enables society to become sustainable. First, at the stage of awareness of smart grid-related technology, government and firm partnerships need to facilitate consumers' beneficial expectancy or perception of the technology through authentic promotion and education, while a systematic approach to reduce risks or barriers, which may result from unknown risky factors, should be promoted and provided to consumers.

Second, at the stage of adoption of smart grid-related technology, it is important that users assess the technology as a challenge or an opportunity for improving their life because challenge appraisal significantly affects their adaptation behaviors. Firms and government need to devise strategies and execute policies facilitating users to evaluate the potential outcomes of smart grid-related technology as a challenge rather than a threat. It is necessary to promote challenge appraisals in order to achieve positive reappraisals through an emotion-focused strategy. Smart grid-related technology is beneficial at the individual level due to economic and convenience aspects, and also promotes public interest in environmental protection, sustainable regional development, and building clean and comfortable villages. The public interest, as well as individuals' private benefits, will induce the challenge appraisals. Authentic and continuous communication with consumers promotes challenge appraisals. Nowadays, many consumers know the importance of policies regarding sustainable energy and climate change. It is not difficult to guess consumers' benefit expectancy affecting challenge appraisals because smart grid-related technology has advantages in the public interest as well as cost savings from the individual perspective.

Finally, at the stage of adaptation and post-adoption, firms and government partnerships need to foster an environment conducive to positive reappraisals and self adaptation behaviors by establishing systematic guidelines and policies. Consumers' challenge appraisals have a significant effect on their positive reappraisal and self adaptation behaviors. For example, convenient and institutionalized communication channels between suppliers and users will be helpful to promote infusion through users' adaptation acts. Consumers' direct and indirect experiences play a role in their positive reappraisal. According to Joo and Kim [1], communication with acquaintances or neighbors who have positive experience with smart grid-related technology facilitates positive indirect experience.

Generalization of research findings depends on representativeness of sample and its size. Data were collected from valid samples selected from a list of population provided by local government, although purposive sampling was used. 226 samples are sufficient to validate the research model and to test 10 hypotheses. However, there may be a limitation in generalization of the research findings. Further research regarding comparison of PV systems and EVs by applying the research model through multi-group analysis is required to identify different relationships by smart grid-related technologies.

Funding: This work was supported by the Dongguk University Research Fund of 2017 and by the Ministry of Education of the Republic of Korea and the National Research Foundation of Korea.

Conflicts of Interest: The author declares no conflict of interest. 


\section{Appendix A. Measurement Items}

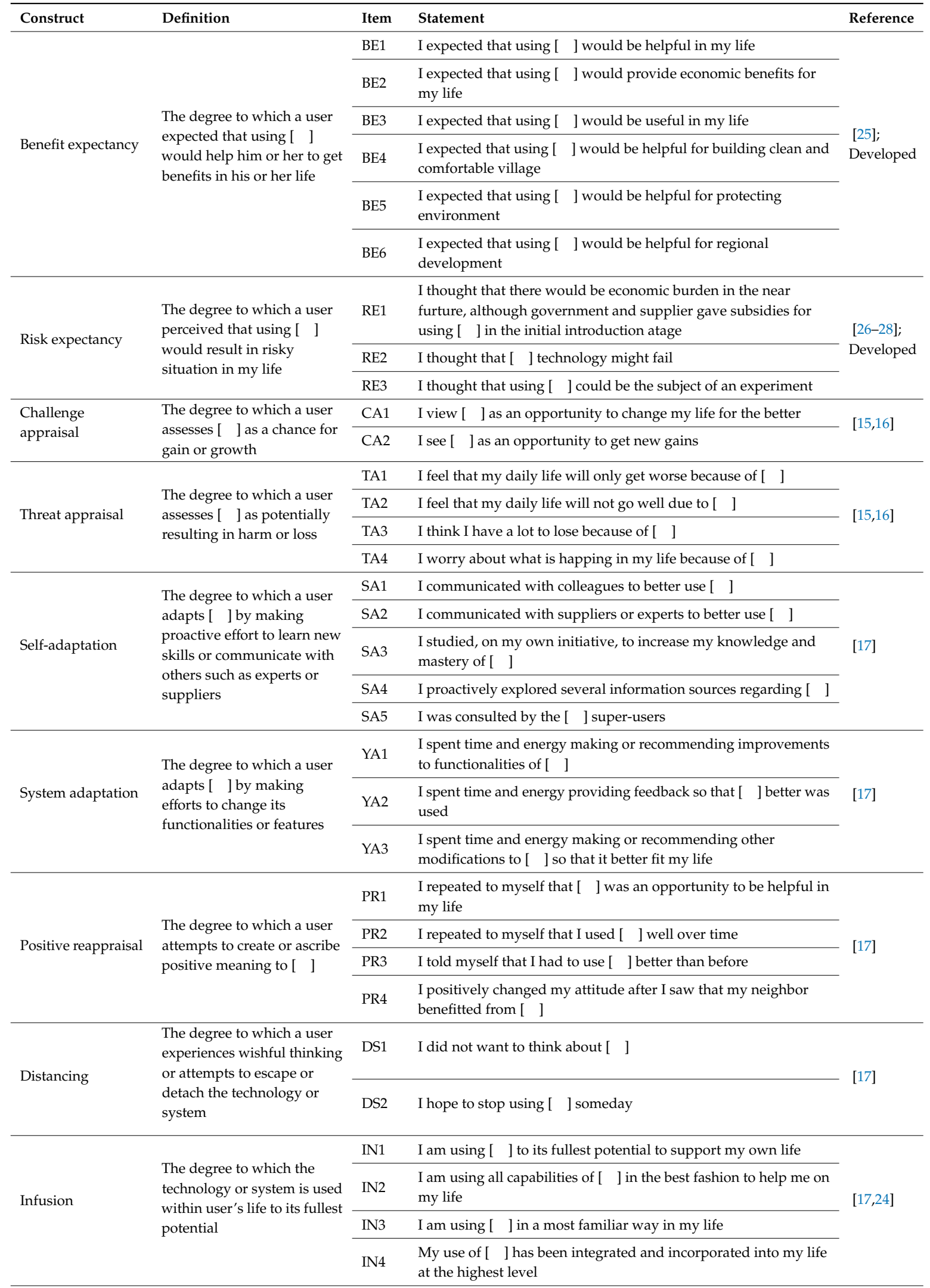

[ ]: smart grid, solar photovoltaic systems, and electric vehicle. 


\section{References}

1. Joo, J.; Kim, L. Strategic guidelines for the diffusion of smart grid technologies through a Korean testbed. Inf. Technol. Dev. 2016, 22, 503-524. [CrossRef]

2. Milchram, C.; van de Kaa, G.; Doorn, N.; Künneke, R. Moral values as factors for social acceptance of smart grid technologies. Sustainability 2018, 10, 2703. [CrossRef]

3. Silvast, A.; Williams, R.; Hyysalo, S.; Rommetveit, K.; Raab, C. Who 'uses' smart grids? The evolving nature of user representations in layered infrastructures. Sustainability 2018, 10, 3738. [CrossRef]

4. Mah, D.N.; Vleuten, J.M.V.D.; Jasper, C.M.I.; Peter, R.H. Governing the transition of socio-technical systems: A case study of the development of smart grids in Korea. Energy Policy 2012, 45, 133-141.

5. National Institute of Standards and Technology (NIST). NIST Framework and Roadmap for Smart Grid Interoperability Standards, Release 2.0; IST Special Publication 1108R2; NIST: Gaithersburg, MD, USA, 2012.

6. Apostolopoulos, P.A.; Tsiropoulou, E.E.; Papavassiliou, S. Demand response management in smart grid networks: A two-stage game-theoretic learning-based approach. Mob. Netw. Appl. 2018, 1-14. [CrossRef]

7. Palensky, P.; Dietrich, D. Demand side management: Demand response, intelligent energy systems, and smart loads. IEEE Trans. Ind. Inform. 2011, 7, 381-388. [CrossRef]

8. Sierzchula, W.; Bakker, S.; Maat, K.; van Wee, B. The influence of financial incentives and other socio-economic factors on electric vehicle adoption. Energy Policy 2014, 68, 183-194. [CrossRef]

9. Xiong, Y.; Yang, X. Government subsidies for the Chinese photovoltaic industry. Energy Policy 2016, 99, 111-119. [CrossRef]

10. Lazarus, R.S.; Folkman, S. Stress, Appraisal, and Coping; Springer Publishing Company: New York, NY, USA, 1984.

11. Ministry of Knowledge Economy and Korea Smart Grid Institute. “Korea's Smart Grid Roadmap 2030: Laying the Foundation for Low Carbon, Green Growth by 2030", Pamphlet, (Seoul, 2010). Available online: https: //www.unescap.org/sites/default/files/37.\%20CS-Republic-of-Korea-smart-grid-development.pdf (accessed on 20 June 2019).

12. Beaudry, A.; Pinsonneault, A. Understanding user responses to information technology: A coping model of user adaptation. MIS Q. 2005, 29, 493-524. [CrossRef]

13. Beaudry, A.; Pinsonneault, A. Advancing the Theory of Infusion (an Appropriation Model of the Infusion Process). 1999. Available online: https://pdfs.semanticscholar.org/c625/ 8dec06494b2779d624d9edc859e9616989d1.pdf (accessed on 15 May 2019).

14. Liang, H.; Xue, Y. Avoidance of information technology threats: A theoretical perspective. MIS Q. 2009, 33, 71-90. [CrossRef]

15. Fadel, K.J.; Brown, S.A. Information systems appraisal and coping: The role of user perceptions. Commun. Assoc. Inf. Syst. 2010, 26, 107-126. [CrossRef]

16. Fadel, K.J. User adaptation and infusion of information systems. J. Comput. Inf. Syst. 2012, 52, 1-10.

17. Fadel, K.J. The role of appraisal in adapting to information systems. J. Organ. End User Comput. 2012, 24, 18-40. [CrossRef]

18. D'Arcy, J.; Herath, T.; Shoss, M.K. Understanding employee responses to stressful information security requirements: A coping perspective. J. Manag. Inf. Syst. 2014, 31, 285-318. [CrossRef]

19. Stein, M.; Newell, S.; Wagner, E.L.; Galliers, R.D. Coping with information technology: Mixed emotions, vacillation, and nonconforming use patterns. MIS Q. 2015, 39, 367-392. [CrossRef]

20. Bhattacherjee, A.; Davis, C.J.; Connolly, A.J.; Hikmet, N. User response to mandatory IT use: A coping theory perspective. Eur. J. Inf. Syst. 2017, 26, 1-21. [CrossRef]

21. Gaudioso, F.; Turel, O.; Galimberti, C. The mediating roles of strain facets and coping strategies in translating techno-stressors into adverse job outcomes. Comput. Hum. Behav. 2017, 69, 189-196. [CrossRef]

22. Venkatesh, V.; Morris, M.G.; Davis, G.B.; Davis, F.D. User acceptance of information technology: Toward a unified view. MIS Q. 2003, 27, 425-478. [CrossRef]

23. Zmud, R.W.; Apple, E.L. Measuring technology incorporation/infusion. J. Prod. Innov. Manag. 1992, 9, 148-155. [CrossRef]

24. Cooper, R.B.; Zumd, R.W. Information technology implementation research: A technological diffusion approach. Manag. Sci. 1990, 36, 739-758. [CrossRef] 
25. Jones, E.; Sundaram, S.; Chin, W. Factors leading to sales force automation use: A longitudinal analysis. J. Pers. Sell. Sales Manag. 2002, 22, 145-156.

26. Jacoby, J.; Kaplan, L.B. The components of perceived risk. Adv. Consum. Res. 1972, 3, 382-383.

27. Littler, D.; Melanthiou, D. Consumer perceptions of risk and uncertainty and the implications for behaviour towards innovative retail services: The case of Internet banking. J. Retail. Consum. Serv. 2006, 13, 431-443. [CrossRef]

28. Yang, Q.; Pang, C.; Liu, L.; Yen, D.C.; Tarn, J.M. Exploring consumer perceived risk and trust for online payments: An empirical study in China's younger generation. Comput. Hum. Behav. 2015, 50, 9-24. [CrossRef]

29. Groomes, D.A.G.; Leahy, M.J. The relationships among the stress appraisal process, coping disposition, and level of acceptance of disability. Rehabil. Couns. Bull. 2002, 46, 14-23. [CrossRef]

30. Marakhimov, A.; Joo, J. Consumer adaptation and infusion of wearable devices for healthcare. Comput. Hum. Behav. 2017, 76, 135-148. [CrossRef]

31. Roldán, J.L.; Sánchez-Francoa, M.J.; Realb, J.C. From frequency of use to social integration: The mediation of routinization and infusion in Tuenti community. Eur. Res. Manag. Bus. Econ. 2017, 23, 63-69. [CrossRef]

32. Hair, J.F. Multivariate Data Analysis; Pearson College Division: London, UK, 2010.

33. Nunnally, J.C.; Bernstein, I.H. Psychometric Theory, 3rd ed.; McGraw-Hill: New York, NY, USA, 1994.

34. Podsakoff, P.M.; MacKenzie, S.B.; Lee, J.; Nathan, P. Common method biases in behavioral research: A critical review of the literature and recommended remedies. J. Appl. Psychol. 2003, 88, 879-903. [CrossRef]

35. Fornell, C.; Larcker, D.F. Evaluating structural equation models with unobservable variables and measurement error. J. Mark. Res. 1981, 18, 39-50. [CrossRef]

36. Henseler, J.; Ringle, C.M.; Sarstedt, M. Testing measurement invariance of composites using partial least squares. Int. Mark. Rev. 2016, 33, 405-431. [CrossRef]

37. Garson, G.D. Partial Least Squares: Regression and Structural Equation Models; Statistical Associates Publishers: Asheboro, NC, USA, 2016.

38. Hu, L.; Bentler, P.M. Cutoff criteria for fit indexes in covariance structure analysis: Conventional criteria versus new alternatives. Struct. Equ. Model. 1999, 6, 1-55. [CrossRef]

39. Chin, W.W. The partial least squares approach for structural equation modeling. In Modern Methods for Business Research; Macoulides, G.A., Ed.; Lawrence Erlbaum Associates: Mahwah, NJ, USA, 1998; pp. 295-336. 